\title{
Effects of Nosema ceranae and thiametoxam in Apis mellifera: A comparative study in Africanized and Carniolan honey bees
}

\author{
Ales Gregorc a, *, Elaine C.M. Silva-Zacarin ${ }^{\text {b, }}{ }^{* *}$, Stephan Malfitano Carvalho ${ }^{\text {, }}$ \\ Doris Kramberger ${ }^{d}$, Erica W. Teixeira ${ }^{e}$, Osmar Malaspina ${ }^{f}$ \\ a Agricultural Institute of Slovenia, Ljubljana, Slovenia \\ ${ }^{\mathrm{b}}$ Universidade Federal de São Carlos (UFSCar), Campus Sorocaba, SP, Brazil \\ ${ }^{\mathrm{c}}$ Universidade Federal de Uberlândia, Uberlândia, Minas Gerais, Brazil \\ ${ }^{\mathrm{d}}$ University of Maribor, Faculty of Agriculture and Life Sciences, Slovenia \\ e Laboratório de Sanidade Apícola (LASA), Agência Paulista de Tecnologia dos Agronegócios (APTA), Pindamonhangaba, São Paulo, Brazil \\ ${ }^{\mathrm{f}}$ Centro de Estudos de Insetos Sociais (CEIS), Instituto de Biociências, UNESP, Campus de Rio Claro, São Paulo, Brazil
}

\section{A R T I C L E I N F O}

\section{Article history:}

Received 6 October 2015

Received in revised form

7 December 2015

Accepted 8 December 2015

Available online 15 January 2016

Handling Editor: David Volz

\section{Keywords:}

Neonicotinoid

Pathogen

Midgut

Cell death

Worker honey bee

\begin{abstract}
A B S T R A C T
Multiple stressors, such as chemicals and pathogens, are likely to be detrimental for the health and lifespan of Apis mellifera, a bee species frequently exposed to both factors in the field and inside hives. The main objective of the present study was to evaluate comparatively the health of Carniolan and Africanized honey bees (AHB) co-exposed to thiamethoxam and Nosema ceranae ( $N$. ceranae) spores. Newly-emerged worker honey bees were exposed solely with different sublethal doses of thiamethoxam ( $2 \%$ and $0.2 \%$ of LD50 for AHB), which could be consumed by bees under field conditions. Toxicity tests for the Carniolan bees were performed, and the LD50 of thiamethoxam for Carniolan honey bees was $7.86 \mathrm{ng}$ bee $^{-1}$. Immunohistological analyses were also performed to detect cell death in the midgut of thiamethoxam and/or $N$. ceranae treated bees. Thiamethoxam exposure had no negative impact on Nosema development in experimental conditions, but it clearly inhibited cell death in the midgut of thiamethoxam and Nosema-exposed bees, as demonstrated by immunohistochemical data. Indeed, thiamethoxam exposure only had a minor synergistic toxic effect on midgut tissue when applied as a low dose simultaneously with $N$. ceranae to AHB and Carniolan honey bees, in comparison with the effect caused by both stressors separately. Our data provides insights into the effects of the neonicotenoid thiamethoxam on the AHB and Carniolan honey bee life span, as well as the effects of simultaneous application of thiamethoxam and $N$. ceranae spores to honey bees.
\end{abstract}

() 2016 Published by Elsevier Ltd.

\section{Introduction}

Among several insecticides used in agriculture against insect pests, special attention is given to a second generation neonicotinoid thiametoxam, which has systemic action in plants (Maienfisch et al., 2001). Because this insecticide is systemic, it should be considered hazardous to pollinators because nectar, pollen and exudates could become contaminated (Girolami et al., 2009; Stoner and Eitzer, 2012). An accumulation of

\footnotetext{
* Corresponding author. Agricultural Institute of Slovenia, Hacquetova 17, 1000 Ljubljana, Slovenia.

** Corresponding author.

E-mail address: Ales.Gregorc@kis.si (A. Gregorc).
}

neonicotinoids occurs in hive products, and thus young emerging honey bees can be chronically exposed to sublethal doses of thiamethoxam (Pillin et al., 2013), which induces significant short-term impacts at the colony level, resulting in decreased colony performance and productivity (Sandrock et al., 2014). Africanized and European honeybees are the same specie (Apis mellifera), and they are classified as different races or sub-species. Several differences were established between AHB and European bees, including morphological, behavioral, genetic, resistance to Varroa parasitism (Calderon et al., 2010). Comparative analysis of the effects of pesticide and pathogen are needed on the tissue level to add information about the mode of action of insecticide and pathogen in both bee races.

Neonicotinoids act on the insect nervous system through agonistic actions on nicotinic acetylcholine receptors (Tan et al., 
2007). For European honeybees, the LD50 for oral administration of thiamethoxam over $48 \mathrm{~h}$ is $5 \mathrm{ng}$, and LD50 for contact administration over $24 \mathrm{~h}$ is $29 \mathrm{ng}$ (Decourtye et al., 2005). Furthermore, the LD50 of thiamethoxam for newly emerged AHBs is $4.28 \mathrm{ng}$ bee $^{-1}$ (Oliveira et al., 2014).

Multiple stressors have been identified as a potential cause of individual bee or colony mortality (Goulson et al., 2015), including pesticides and pathogens. A combination of various pathogens has been documented as a contributing cause to bee mortality (CoxFoster et al., 2007; Higes et al., 2008). In addition to pesticides, Nosema ceranae, a microsporidium that infects the midgut cells of several species of the Apis genus (Higes et al., 2007; Garcia-Palencia et al., 2010), results in reduced colony strength and winter mortality, without any previous evident precocious clinical symptoms (Higes et al., 2008; Botias et al., 2013). N. ceranae also induces modifications on bee physiology (Dussaubat et al., 2010).

Persistent exposure to pesticides and pathogens threatens honey bee survival. Interaction between pesticides and Nosema microspores has an impact on bee health (Alaux et al., 2010; Aufauvre et al., 2012) and causes a reduction of bee lifespan (Vidau et al., 2011), indicating that Nosema potentially interacts with environmental stressors such pesticides. Knowledge about the effects of interaction among different pathogens or pesticides within the hives is crucial for understanding the bee disease dynamics and bee mortality, which appear in recent years (vanEngelsdorp et al., 2009; Cornman et al., 2012).

Thiamethoxam binds to the nicotinic acetylcholine receptor in the insect's nervous system and may affect honey bees through contaminated food. Together with Nosema spores which is per os infectious agent potentially could induce changes in bee tissues, especially in the midgut, which is an absorptive organ and thus potentially the first affected organ for chemical compounds. It is therefore necessary to study the toxic effects on bees and the changes in the honey bee midgut on the cellular level induced by both oral administration of thiamethoxam and inoculation with $N$. ceranae spores. We previously used several cell death assays to determine the toxic effects of various pesticides on honey bee. The first method we used to determine the progression of cell death in situ was the TUNEL (terminal deoxynucleotidyl transferasemediated dUTP nick end labeling) assay, which enables the visualization of fragmented DNA in the nucleus (Gavrieli et al., 1992). Previous studies have successfully used the terminal TUNEL technique to detect cell death in the honey bee midgut (Gregorc and Bowen, 2000). As different methods assaying DNA fragmentation (TUNEL technique) can indicate different levels of cell death in tissues, we used two methods of cell death detection in our experiments. A previous report found that in different human tissues the 'in situ cell death detection kit AP' was unable to differentiate between apoptosis and necrosis (Matylevitch et al., 1998). Our experimental design explores the interaction between thiamethoxam and $N$. ceranae infection to demonstrate survival rates of both Apis mellifera carnica and Africanized Apis mellifera exposed to thiamethoxam and $N$. ceranae and to further evaluate both types of cell death using two TUNEL immunohistological methods. Our further aim is also to compare the thiamethoxam and $N$. ceranae effect in both honey bee subspecies. The honey bee Apis mellifera carnica Pollmann (commonly known as the "Carniolan bee") and the Africanized honeybee (AHB, hybrid of A. m. scutellata from Africa and European subspecies) live in different regions with different climatic conditions. Thus, a comparative evaluation of response of these subspecies to insecticides and pathogens is important for determining the role of stressors on the physiological health of a bee species exhibiting considerable variability in defensive behavior.

The main objectives of this study were: (1) to provide toxicological data of Carniolan honey bees exposed to different concentrations of thiamethoxam; (2) and to determine the survival rates of Carniolan and AHB simultaneously exposed to sublethal concentrations of thiamethoxam and N. ceranae; and (3) to evaluate the potential differences in the mechanism of action of thiamethoxam and $N$. ceranae spores on the midgut tissue of Carniolan bees compared to the AHB.

\section{Material and methods}

\subsection{Experimental bees, treatments and sampling}

Bioassays were conducted at the Agricultural institute of Slovenia, Ljubljana, Slovenia, and at the Center of Study about Social Insects (CEIS-UNESP), Rio Claro, São Paulo State, Brazil. Frames of capped brood were obtained from healthy colonies to provide a supply of newly emerged honey bees (A. mellifera carnica Polm.) free of Nosema for all trials (confirmed by PCR following the method from Martin-Hernandez et al., 2007).

Worker honey bees emerging from the brood comb in an incubator were obtained as a mixture from three colonies. After emergence, $24 \mathrm{~h}$-old worker bees were confined to cages. The bees were starved for $2 \mathrm{~h}$ before starting the toxicity and inoculation procedures.

\subsection{Experiment design}

Newly emerged worker honey bees were divided in groups and individually treated as later described. Workers were kept into plastic cups (cages) and maintained at $30 \pm 1{ }^{\circ} \mathrm{C}$ with a $70 \pm 10 \%$ of $\mathrm{RH}$ in the dark. For all experiments, the caged bees were fed per os, using micropipette, with specific treatment solution and all bees in the cages were fed with sucrose water solution (1:1) ad libitum.

\subsubsection{Acute toxicity test of thiamethoxam for Carniolan honey bees inoculated per os}

A thiamethoxam stock solution (1000 ng a.i./ $\mu \mathrm{l})$ was prepared using acetone as an initial solvent. Experimental treatment concentrations were prepared by further dilutions of a diet of sucrose water solution (1:1). Newly emerged bees were separated into seven groups, with five replicates for each group. In each replicate there were 20 bees. Bees in each treatment group were individually inoculated with $2 \mu \mathrm{l}$ of sugar solution containing thiamethoxam. In group 1, bees received $42.80 \mathrm{ng}$; bees in group 2 received $21.40 \mathrm{ng}$; bees in group 3 received $10.70 \mathrm{ng}$; bees in group 4 received $5.35 \mathrm{ng}$; and bees in group 5 received $2.68 \mathrm{ng}$ thiamethoxam. The bees in the cages of groups 6 and 7 were control bees individually fed with $2 \mu \mathrm{l}$ sugar solution in water (1:1). Dead bees in both the treatment and control groups were counted after 24 and $48 \mathrm{~h}$. Acute toxicity test was performed only in Carniolan bee, because toxicity test in AHB was conducted in previous experiments (Oliveira et al., 2014). Bee mortality analyses were performed by ANOVA (analysis of variance) to test whether the treatments affected the bees. When necessary, ANOVA was followed by a Tukey test for pair wise comparisons. Statgraphic plus software programme was used, and $\mathrm{P}=0.05$ as the significance threshold in all statistical analyses was considered.

\subsubsection{Toxicity test with Carniolan and $A H B$ bees}

2.2.2.1. Obtention of $N$. ceranae spores. $N$. ceranae spores were obtained from the same geographic origin as bees. Thus, for Carniolan bees, $N$. ceranae were obtained from the colony maintained at the experimental apiary at the Agricultural Institute of Slovenia, Ljubljana, Slovenie. The AHB workers, used as a source of $N$. ceranae spores, were obtained from the colony maintained at the apiary of APTA, located in Pindamoguangada, São Paulo State, Brazil. 
Molecular characterization of the spore inoculums, in both countries, was performed using PCR (Higes et al., 2007) to confirm that the spores were correspondent to $N$. ceranae.

To get Nosema spores for experimental infection of bees, workers were collected from infected colonies and their midgut were dissected and macerated. Macerate containing spores was washed three times by centrifugation in Insect Ringer's solution. Concentration of spores was determined by counting spores in a Neubauer chamber under light microscopy. The lowest infective dose of 60,000 spores per bee was applied. Spore inoculums and/or thiamethoxam solution were prepared fresh for inoculation and sterile filter pipette tips for individual bees were used. Each day, dead bees were removed from cages and counted.

2.2.2.2. Exposure to thiamethoxam and/or N. ceranae spores inoculation. The chosen doses of thiamethoxam were calculated from established LD50 for AHB (Oliveira et al., 2014) and correspond to $0.2 \%$ and $2 \%$ of LD50. Both doses are in agreement with the average maximum neonicotinoid concentrations found in pollen and nectar consumed by adult honey bees (Godfray et al., 2014). A toxicity test for the honey bees was performed using two thiamethoxam doses individually administered by oral administration using a micropipette (per os inoculation). The doses administered to the bees in the first and second experimental group were: I) $0.0856 \mathrm{ng}^{\mathrm{bee}}{ }^{-1}(1 / 50$ or $2 \%$ of LD50); II) $0.00856 \mathrm{ng} \mathrm{bee}^{-1}$ ( $1 / 500$ or $0.2 \%$ of LD50). Bees in the third and fourth group received the doses of thiamethoxam and additionally $60.000 \mathrm{~N}$. ceranae spores: III) $0.0856 \mathrm{ng}$ bee $^{-1}$ of thiamethoxam plus Nosema spores; IV) $0.00856 \mathrm{ng}^{b^{-1}}$ of thiamethoxam plus Nosema. Bees in the fifth group received $N$. ceranae spores only and the control group of untreated bees received sucrose water solution (1:1). The volume of the treatment solution with thiamethoxam was $2 \mu \mathrm{l}$ and the volume of treatment solution with thiamethoxam and $N$. ceranae spores was $4 \mu \mathrm{l}$, which included $2 \mu$ l thiamethoxam in a sucrose water solution (1:1) and $2 \mu \mathrm{l}$. ceranae spore suspension.

Each experimental group consisted of five replicates, with 15 bees in each one. The experiment established the mortality rate of inoculated workers, thus only dead workers were sampled daily.

\subsection{Immunohistological analyses}

We also populated six cages in parallel to conduct immunohistological analyses. Thirty bees in each cage were individually per os inoculated, using the same protocol for each experimental group as described in 2.2.2.1. Thirty bees in the first cage were inoculated with the doses of thiamethoxam: I) $0.0856 \mathrm{ng} \mathrm{bee}^{-1}$ or II) $0.00856 \mathrm{ng} \mathrm{bee}^{-1}$; in the third and fourth cages, bees received a high and a low dose of thiamethoxam mixed with 60,000 N. ceranae spores, respectively. Bees in the fifth cage received $N$. ceranae spores only and the control bees in the sixth cage received sucrose water solution (1:1).

\subsubsection{Immunohistochemical analyses}

For immunohistochemical procedure, worker bees were randomly sampled from each experimental group at different times post-inoculation: 5 th, 10 th, 17 th and 20 th days. Three bees of each collection time for each experimental group were anesthesed by cold temperature for few minutes and dissected in order to remove the midgut.

Midguts were fixed in 10\% formalin, dehydrated in ethanol and embedded in paraffin wax for the posterior immunohistochemistry procedure. The $5-\mu \mathrm{m}$ sections were then deparaffinized and processed per the instructions of the two kits used: the 'In situ cell death detection kit, AP' (ISCDDK) (Roche, Ljubljana, Slovenia) and the 'ApoTag' colorimetric apoptosis detection system' (Millipore,
Labena, Ljubljana, Slovenia).

The EnVision System alkaline phosphatase kit (Dako, Labormed, Ljubljana, Slovenia) was used to obtain a red-colored precipitate in sections submitted to ISCDDK assay. The sections were counterstained with hematoxylin. TUNEL-positive cells appeared red, which are indicated by a reaction product localized to the nucleus and indicative of cell death, and the TUNEL-negative nuclei of healthy cells appeared blue.

Histological sections submitted to ApopTag in situ apoptosis detection kit were incubated with diaminobenzidine tetrahydrochloride (DAB). The sections were counterstained with hematoxylin. TUNEL-positive cells appeared brown, which are indicated by a reaction product localized to the nucleus and indicative of cell death, and the TUNEL-negative nuclei of healthy cells appeared blue.

In both assays for cell death detection a control labeling was achieved by substituting the deoxynucleotidyl transferase (TdT) enzyme with phosphate buffered saline (PBS) during TUNEL reaction. Sections were mounted in Faramount aqueous mounting medium (Dako). All slides were analyzed and photodocumented with a bright field light microscope.

Some slides containing deparaffinized midgut sections from experimental groups inoculated with Nosema spores were submitted to incubation with 4',6-diamidino-2-phenylindole (DAPI) at $2 \mathrm{mg} / \mathrm{mL}$ for $30 \mathrm{~min}$, at room temperature, and washed in distilled water. Sections were mounted in Faramount aqueous mounting medium (Dako) and analyzed under epi-fluorescence microscopy.

\subsubsection{Semi-quantitative analysis of cell death}

TUNEL-labeled tissue slides were used for quantification of cell type and impending cell death using ISCDDK and ApopTag kits. For each experimental group of bees, approximately 300 total cells from each individual (three bees at different collection times per group) were counted in random fields within the tissue on different slides. The results were expressed as the proportion of cells with positive staining. To confirm reproducibility, $25 \%$ of the slides were chosen randomly and scored twice. The proportion of cells with positive staining was converted in scores, based on the study by Bernet et al. (1999) with the following score adaptations: (0) sporadic positive cells; (2) 5-15\% positive cells; (4) 20-55\% positive cells; (6) $60-90 \%$ positive cells.

\section{Results}

\subsection{Acute toxicity test of thiamethoxam for Carniolan honey bees inoculated per os}

Acute toxicity test was performed only in Carniolan bee, because toxicity test in AHB was conducted in previous study performed by our research group (Oliveira et al., 2014).

The numbers of dead Carniolan bees were recorded after 24 and $48 \mathrm{~h}$ exposure to various concentrations of thiamethoxam treatment (Fig. 1). A strong positive linear correlation $(r=0.84)$ was found between thiamethoxam concentration and acute bee mortality $24 \mathrm{~h}$ after exposure.

\subsection{Toxicity test with Carniolan and AHBs}

When bees were exposed to low doses of thiamethoxam and additionally to $N$. ceranae spores, no differences in mortality rate were observed. Carniolan honey bees gradually died during the period of 30 days. Individual bees treated with thiamethoxam and Nosema survived up to 40 days. Differences in bee mortality were not found even though experimental bees survived more than 30 days. Fig. 2 shows a summary of bee survival for each of the five 


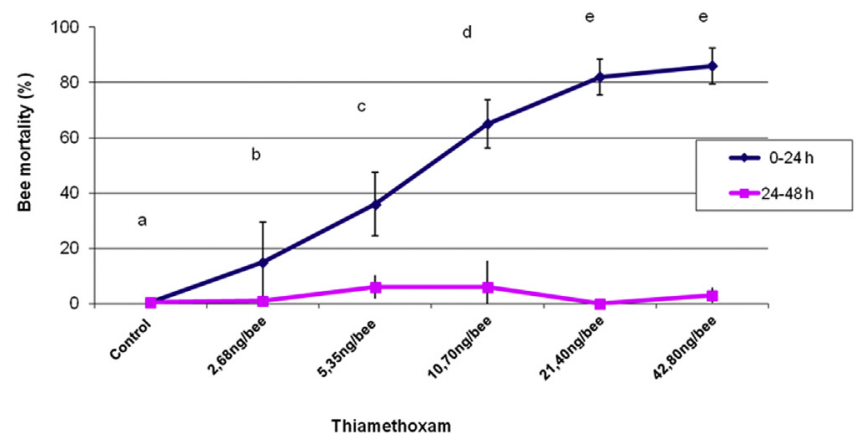

Fig. 1. Mean cumulative mortality of groups treated with various concentrations of thiamethoxam. Each group contained 5 cages. Bees in each treatment group received various concentrations of thiamethoxam, ranging from $2.68 \mathrm{ng} \mathrm{bee}^{-1}$ to $42.8 \mathrm{ng} \mathrm{bee}^{-1}$. Cumulative mortalities are shown for two time points, 24 and $48 \mathrm{~h}$ after exposure. Control bees received only a sugar solution. Letters indicate that the Tukey tests $(P<0.05)$ established that the bee mortality rates between thiamethoxam treatment groups were not significantly different. Bars indicate standard deviation.

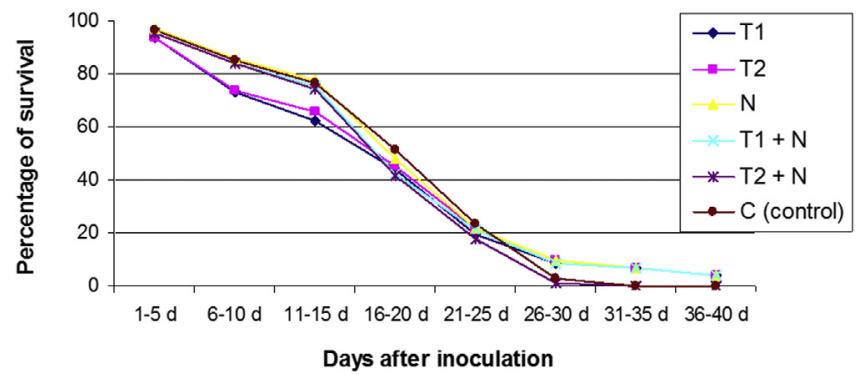

Fig. 2. Mean cumulative survival of Carniolan honey bees per treatment group after exposure for indicated times. Each treatment group contained 5 cages. Bees in each treatment group were treated with various concentrations of thiamethoxam and $N$. ceranae spores as indicated: $0.0856 \mathrm{ng} \mathrm{bee}^{-1}$ (T1 group), $0.00856 \mathrm{ng}^{-1} \mathrm{bee}^{-1}$ (T2), high dose of thiamethoxam and $60,000 \mathrm{~N}$. ceranae spores $(\mathrm{T} 1+\mathrm{N})$ and a low dose of thiamethoxam and $60,000 \mathrm{~N}$. ceranae spores $(\mathrm{T} 2+\mathrm{N})$. Bees in the control group received only a sugar solution. Survival rates are indicated in five day periods.

treatment groups.

The AHBs gradually died during a period of 10 days. Fig. 3 shows a summary of bee survival for each of the five treatment groups.

\subsection{Nosema quantification}

\subsubsection{Carniolan honey bee}

After inoculation with Nosema spores, the number of spores after five days averaged at 30,000 spores per bee $\left(0.030 \times 10^{6}\right)$ in bees which received only Nosema. The same number was observed in bees that received Nosema plus a low dose $\left(0.00856 \mathrm{ng}^{-1} \mathrm{bee}^{-1}\right)$ of thiamethoxam. In contrast, the Nosema spore load in bees inoculated only with spores was higher than in bees simultaneously inoculated with Nosema and the high dose $\left(0.0856 \mathrm{ng}^{-1}\right.$ bee $\left.^{-1}\right)$ of thiamethoxam $(P<0.05)$. Ten days after inoculation, the Nosema spore counts in groups of bees that received only Nosema spores, Nosema spores plus the high dose of thiamethoxam and Nosema spores plus a low dose of thiamethoxam were $0.94 \times 10^{6}$ $\left( \pm 1.12 \times 10^{6}\right), 1.79 \times 10^{6}\left( \pm 2.64 \times 10^{6}\right)$, and $0.47 \times 10^{6}\left( \pm 0.92 \times 10^{6}\right)$ spores, respectively. Ten days after inoculation with Nosema plus a high dose of thiamethoxam, this group of bees showed a significant increase $(P>0.05)$ in the number of Nosema spores compared with the spore counts in bees inoculated with spores only or Nosema spores plus a low thiamethoxam dose. In bees that received thiamethoxam without Nosema spores and in the untreated bees, no Nosema spores were found.

\subsection{2. $A H B$}

The number of spores at 5 days post-inoculation with Nosema only was 300,000 spores per bee $\left(0.30 \times 10^{6}\right)$ and 210,000 spores per bee $\left(0.21 \times 10^{6}\right)$ for the group that received Nosema plus a low dose of thiamethoxam. In bees simultaneously inoculated with Nosema and exposed to the high dose of thiamethoxam, the Nosema spore load was 160,000 spores per bee $\left(0.16 \times 10^{6}\right)$. In bees that received thiamethoxam without Nosema spores and in the untreated bees, no Nosema spores were found.

\subsection{Immunohistochemical analysis of the midgut}

ISCDDK and Apoptag Kits presented similar labeling in nuclei of midgut cells. The immunohistochemical data obtained in the groups exposed to various doses of thiamethoxam and concomitant inoculation with Nosema spores are summarized in Table 1. In bees

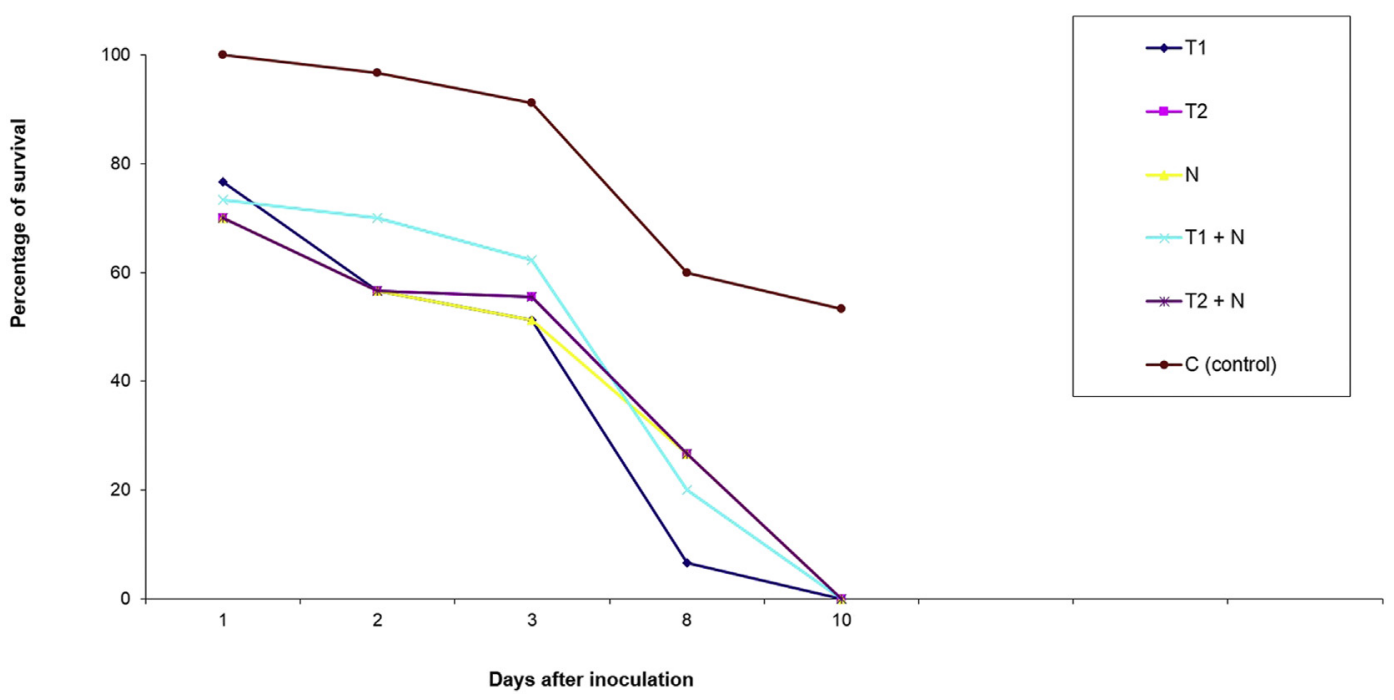

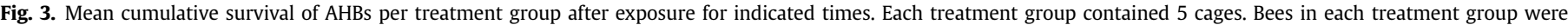

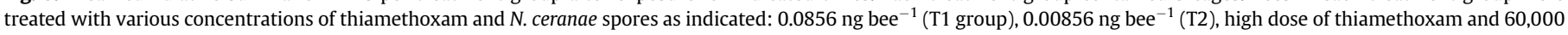
$N$. ceranae spores $(\mathrm{T} 1+\mathrm{N})$ and a low dose of thiamethoxam and $60,000 \mathrm{~N}$. ceranae spores $(\mathrm{T} 2+\mathrm{N})$. Bees in the control group received only a sugar solution. 
Table 1

Semi-quantitative analysis of immunohistochemical (ISCDDK) analysis of cell death in the midgut of Carniolan honey bees (CHB) and Africanized honey bees (AHB).

\begin{tabular}{|c|c|c|c|c|c|c|c|}
\hline \multirow[t]{2}{*}{ Bee } & \multirow[t]{2}{*}{ Days } & \multicolumn{6}{|c|}{ Experimental groups } \\
\hline & & $\mathrm{C}$ (control) & T1 (0.0856 ng bee $\left.{ }^{-1}\right)$ & T2 (0.00856 ng bee $\left.{ }^{-1}\right)$ & $\mathrm{N}(N$. ceranae spores $)$ & $\mathrm{T} 1+\mathrm{N}$ & $\mathrm{T} 2+\mathrm{N}$ \\
\hline \multirow[t]{4}{*}{$\mathrm{CHB}$} & 5 & 2 & 4 & 4 & 6 & 0 & 0 \\
\hline & 10 & 0 & 4 & 4 & 4 & 4 & 0 \\
\hline & 17 & 0 & 4 & 0 & 0 & 0 & 0 \\
\hline & 20 & 0 & 0 & 0 & 0 & 0 & 4 \\
\hline \multirow[t]{2}{*}{ AHB } & 5 & 0 & 4 & 4 & 6 & 0 & 0 \\
\hline & 10 & 0 & 4 & 4 & 4 & 4 & 0 \\
\hline
\end{tabular}

Footnote: Scores represent the proportion of positive cells: (0) sporadic positive cells; (2) 5-15\% positive cells; (4) 20-55\% positive cells; (6) 60-90\% positive cells.

exposed only to thiamethoxam, the amount of immunohistochemically positive cells was not dependent on the dose between 5 and 10 days. However, in bees exposed to the lowest dose of thiamethoxam, the cell death observed in the epithelium of the midgut was similar to the control group (sporadic positive cells), as seen on the 17th day of the bioassay. In contrast, the level of cell death in the midgut epithelium of bees exposed to the highest dose of thiamethoxam remained high on the 17th day of the bioassay.

Notably, the proportion of positive nuclei in midgut digestive cells of the bees treated with both thiamethoxam and Nosema spores was much less than in the groups exposed only to thiamethoxam or inoculated only with Nosema spores. In bees with Nosema infection, clusters of infected cells were dispersed along the midgut epithelium (Fig. 4A, B) on the 5th day after the beginning of the bioassay. By the 10th day, there was a high level of infection along the midgut epithelium and hypertrophic enlargement of the infected digestive cells was observed. Infected cells were also seen detached from the basal membrane and released into the lumen (Fig. 4D). In the midgut of honey bees exposed to the lowest doses of thiamethoxam plus Nosema, the infected cells that were released from the epithelium occupied a larger area of the lumen (Fig. 4E). The peak of infection was reached by the 17th day after the beginning of the bioassay (Fig. 4F). In the bees exposed to both thiamethoxam plus Nosema, the midgut lumen was full of detached infected cells from the basal membrane (Fig. 4G). By the 20th day from the beginning of the bioassay, infected cells were present in the epithelium, but there was no observed increase in releasing of infected cells (Fig. 5). Some areas of the midgut in which no infected cells were observed the thickness of the epithelium showed a decrease (Fig. 5B, C, 5E).

In AHBs, the pattern of infection was similar to that observed for the Carniolan honey bee (Table 1). By the 10th day from beginning of the bioassay, infected cells were observed in the midgut epithelium of bees inoculated with Nosema (Fig. 6A). Sporadic infected cells released into the lumen were positive for ISCDDK, but others were negative.

\section{Discussion}

The toxicological data of the Carniolan honey bees exposed to different concentrations of thiamethoxam indicated that the majority of the deaths in each group of bees occurred within $24 \mathrm{~h}$ of beginning the experiment. Comparing the means/median number of deaths per cage and total number of deaths per group, bee survival clearly increased as thiamethoxam concentration decreased. There were generally more consistently high mortality rates with higher concentrations. Comparison of the LD50 of thiamethoxam determined for the Carniolan honey bee $\left(\right.$ LD50 $\left.=7.86 \mathrm{ng} / \mathrm{bee}^{-1}\right)$ in the current study with the LD50 of thiamethoxam previously determined for the AHB $\left(\operatorname{LD} 50=4.28 \mathrm{ng}\right.$ bee $^{-1}$ ) by Oliveira et al. (2014) indicated that Carniolan bees resist higher doses of thiamethoxam than can AHB. In order to compare the response of the
Carniolan bees and AHB to the same doses of thiamethoxam, we chose two doses of thiamethoxam $\left(0.0856 \mathrm{ng}\right.$ bee $^{-1}$ and $0.00856 \mathrm{ng}$ bee $^{-1}$ ) that were based on the LD50 value, which was previously determined in our laboratory for AHB (Oliveira et al., 2014), corresponding to $1 / 50$ and $1 / 500$ of the $L D 50$, respectively. These doses could be consumed by worker bees in a field scenario, corresponding to $2 \%$ and $0.2 \%$ of $\mathrm{LD} / 50$, respectively (Godfray et al., 2014).

The total mortality of AHB treated bees was observed within 10 days of the bioassays, but not in the Carniolan bees. This indicates that the dose necessary to reach the LD50 in Carniolan honey bees is almost double that described for the AHB. It seems that Carniolan bees used in the experiment were less sensitive to thiamethoxam than AHB, which could be due to larger body weight of European bees. Further studies are necessary to clarify this observed difference.

We observed another difference between the Carniolan and AHB in relation to $N$. ceranae infected versus uninfected bees during the first 5 days of the bioassays. AHB inoculated with $N$. ceranae died faster when compared with uninfected bees, a similar finding described by other authors working with Apis mellifera (Higes et al., 2007; Alaux et al., 2010; Vidau et al., 2011; Aufrave et al., 2012; Dussaubat et al., 2012). A decrease in lifespan is commonly observed in Nosema-infected A. mellifera (Higes et al., 2008; Aufauvre et al., 2014). On the other hand, the survival of the Carniolan honey bee did not decrease in infected versus uninfected bees during the same period of the first 5 days after spore inoculation, probably due lower spore loads when compared with AHB.

Considerable variability has been documented in the longevity of caged bees that were inoculated with Nosema, varying from 8 days (Higes et al., 2007) to 14 days post-infection (Dussaubat et al., 2012), as well as 20 days post-infection (Huang and Solter, 2013). In our experiments, we found variations between both tested subspecies, which could be a result of their genetic divergence and intra-colony rearing differences in both environmental and experimental settings. This includes the availability of nutritional sources and colony management, which, in the first few days, could cause interference with the response of bees to $N$. ceranae infection and to pesticides susceptibility.

In Brazil, $N$. ceranae has been infecting AHB for 34 years, but without any obvious signs of disease (Teixeira et al., 2013). The lack of symptoms of Nosema infection could indicate a greater disease tolerance in the AHB compared with the European honey bee, similar to that described for Varroa destructor (Guzmán-Novoa et al., 1999). In the current study, we found that the caged AHB seemed to be less tolerant to the acute $N$. ceranae infection, and its potential tolerance observed in the field might occur only at the colony level but not at the individual level.

In the current laboratory study performed none of the doses of thiamethoxam increased the mortality rates in Carniolan bees, nor in the bees simultaneously exposed to $N$. ceranae and thiamethoxam. It seems that thiamethoxam has an adverse effect on 

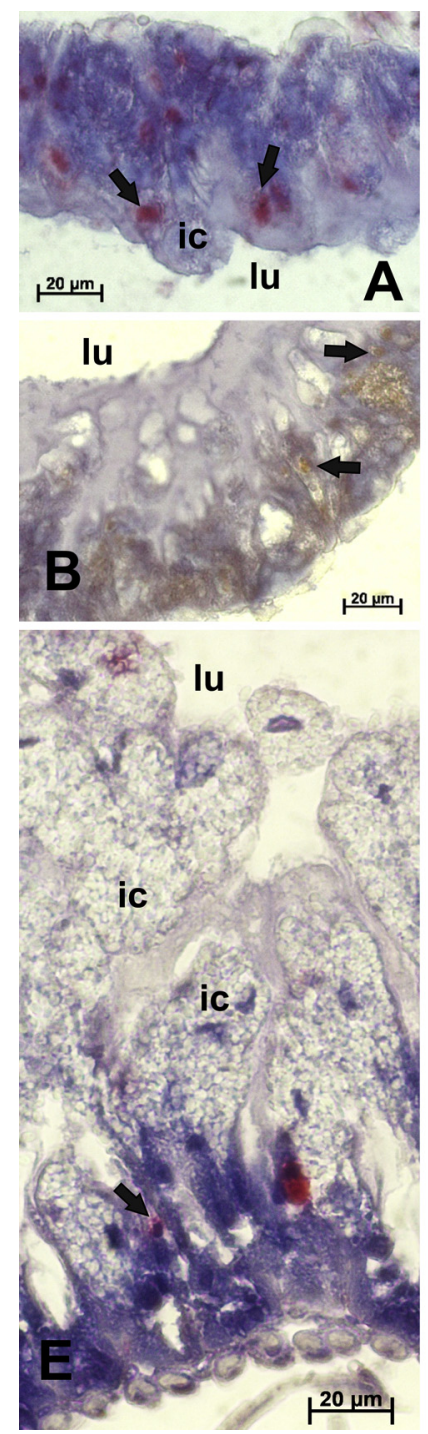
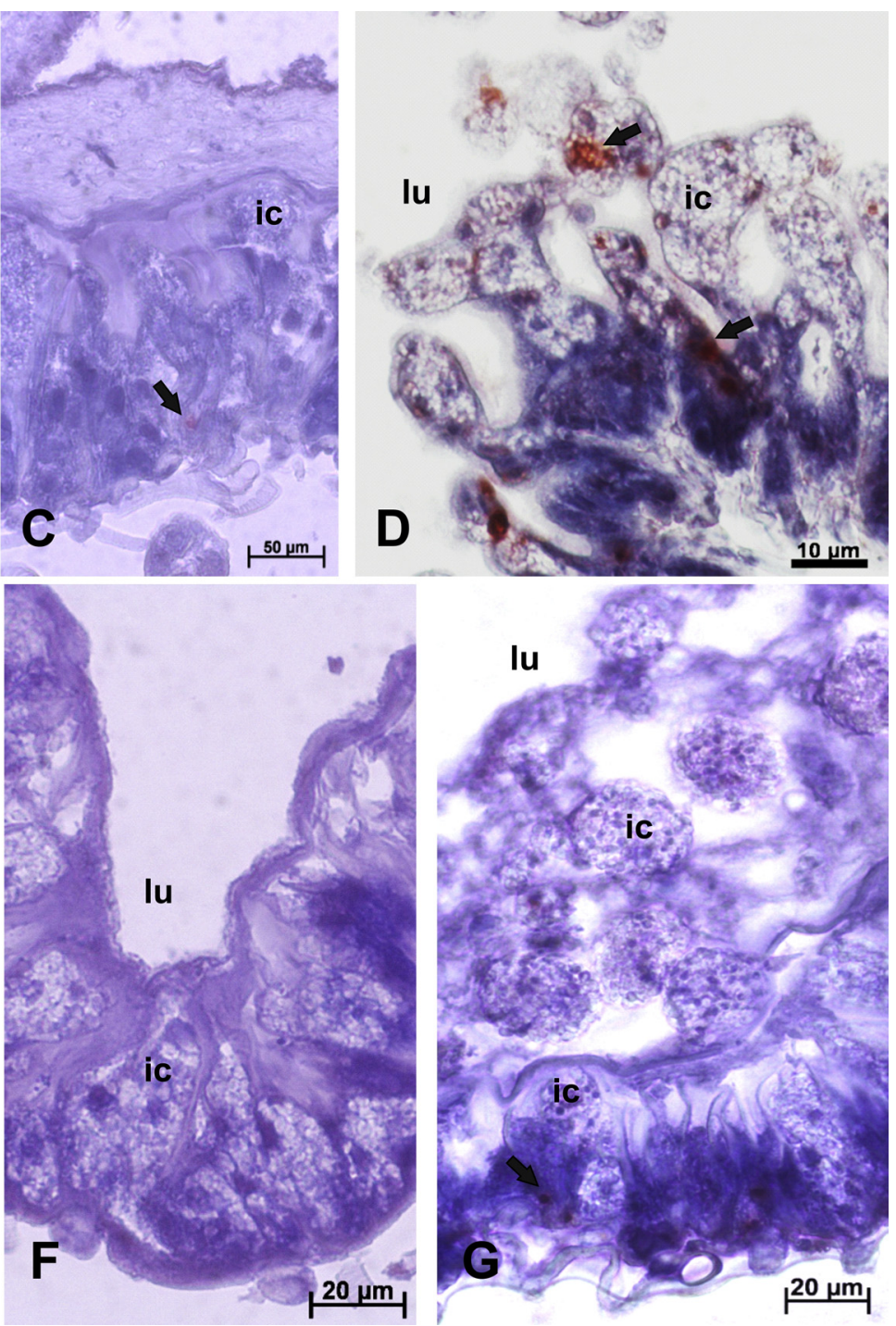

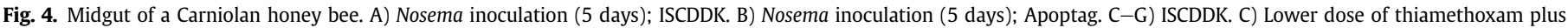

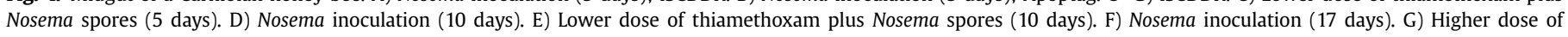
thiamethoxam plus Nosema spores (17 days). Arrow: positive nucleus of midgut cell; ic: infected cell; lu: lumen.

Nosema spore development in the midgut of Carniolan bees. Mortality rates remained at similar levels in the $N$. ceranae-infected and uninfected bees. These results differed from a study by Alaux et al. (2010) on the European A. mellifera from the south-east of France. The interaction between Nosema apis plus $N$. ceranae and imidacloprid increased the mortality rate of workers.

In addition to the differences in the mortality rates induced by Nosema infection in the Carniolan and AHB, there were similarities in terms of histopathological lesions in the infected midgut cells of both bees. The result of the present study indicated that Nosema infection induced a higher cell death rate in comparison with uninfected bees by the 5th day post-infection. This is possibly a defense mechanism in the midgut in the first stages of the parasite infection so that accelerated levels of apoptosis could prevent the spread of infection to neighboring cells, as postulated by James and Green (2002).

The midgut analysis of worker honey bees demonstrated hypertrophic enlargement of the infected digestive cells and an extensive amount of infected cells released into the lumen, observed mainly by 10 days post-infection. The midgut cells of
A. mellifera infected by $N$. ceranae become full of parasitic spores at different stages of development (Higes et al., 2007; García-Palencia et al., 2010), as evidenced by fluorescence microscopy in this study. $N$. ceranae regulate the activity of midgut cells between the 5 th and 8th day post-infection, when midgut cell death decreased in the AHB. In the later period, between the 17th and 20th day postinfection, we observed a reduction in the cell death rate in the midgut of Carniolan bees. A previous study showed that microsporidium interferes with the apoptosis process of the host cell (Del Aguila et al., 2006) and infected cells consequently have a prolonged lifespan, as described for Nosema algerae, which can grow and differentiate within host cells for many days (Scanlon et al., 1999). It was also established that the highly sensitive ISCDDK assay detects both, the apoptosis and necrosis (Gregorc and Bowen, 2000), whereas the ApopTag kit is more specific to apoptotic cell death (Matylevitch et al., 1998). Combined methods can better demonstrate changes in midgut tissue. The pathogenic effect of Nosema can be thus recognized as cell lyses and epithelium destruction, which is seen in late phases of midgut infection (Higes et al., 2007; García-Palencia et al., 2010). In this later phase of 

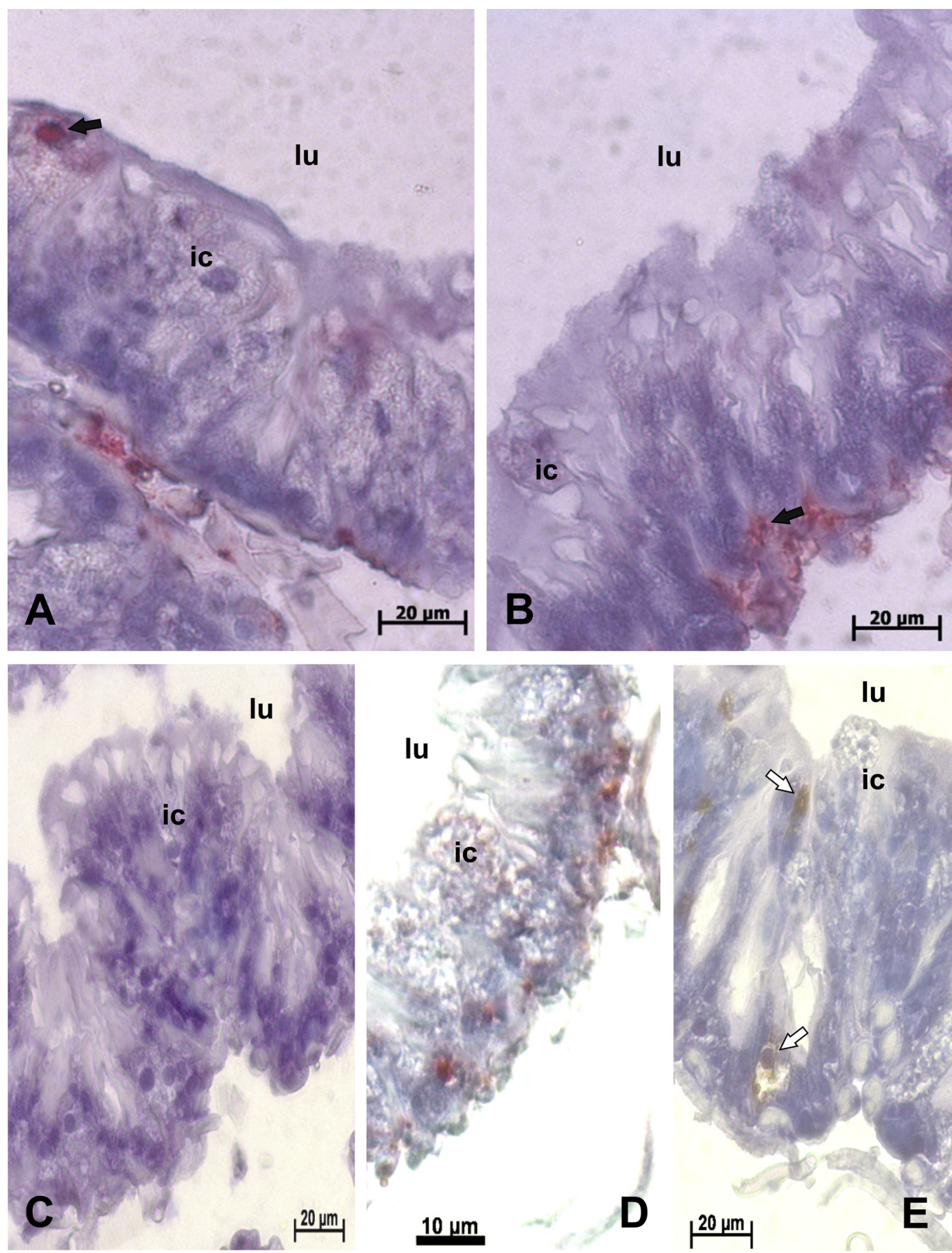

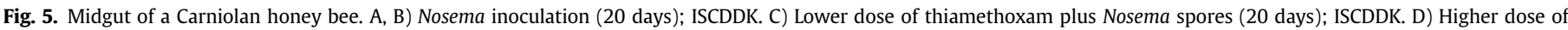

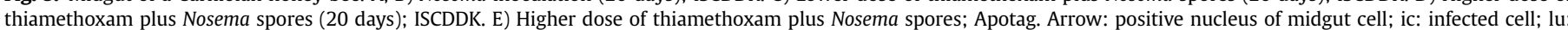
lumen.

infection, as observed in the current study, the reduction in cell renewal was a feature observed in the Nosema-infected midgut by the 20th day post-infection in the Carniolan honey bee. Dussaubat et al. (2012) further demonstrated the inhibition of genes involved in the homeostasis and renewal of gut tissues in response to the microsporidia infection. This tissue degeneration associated with reduced gut epithelium renewal may explain the bee death.

In addition, recent studies suggest that $N$. ceranae can sensitize the honey bees to pesticides and vice versa (Alaux et al., 2010;
Aufauvre et al., 2012, 2014; Pettis et al., 2012; Retschnig et al., 2014; Vidau et al., 2011). Aufauvre et al. (2014) observed that the $N$. ceranae-fipronil combination induced a synergistic effect compared with the effects observed in bees exposed to each stressor alone, regardless of the sequence of exposure to the agents. In addition, a synergistic interaction between the neonicotinoid imidacloprid and Nosema infection was previously observed when both agents were applied simultaneously to young worker honey bees (Alaux et al., 2010). An increase in mortality was also observed 

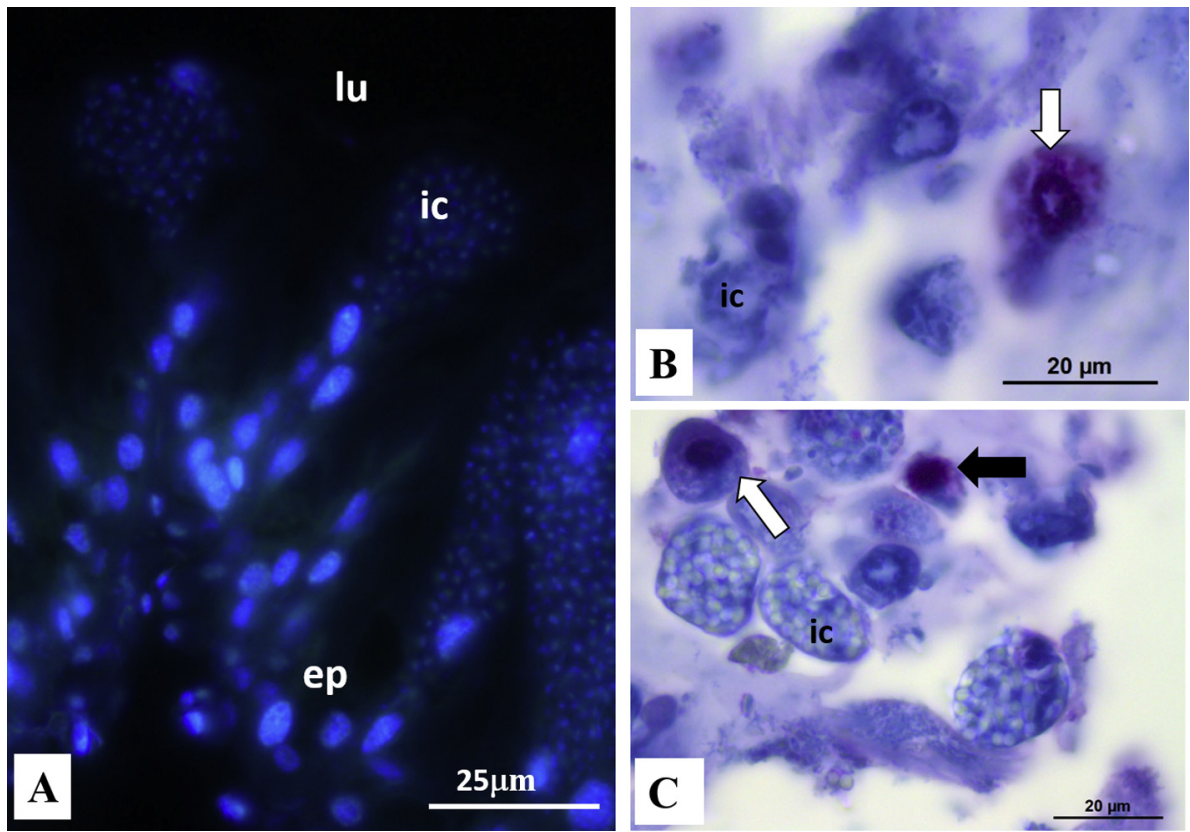

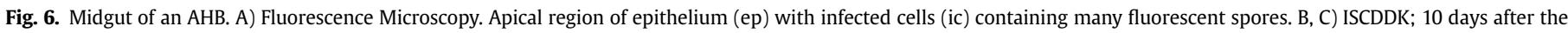

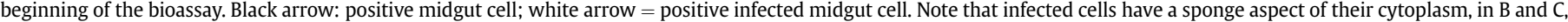
what is labeling by DAPI in A.

in $N$. ceranae-infected worker bees chronically exposed to fipronil and/or thiacloprid (Vidau et al., 2011).

Interestingly, in our experimental conditions, thiamethoxam exposure seemed to have no defined impact on Nosema development, but it clearly inhibited apoptotic cell death in the midgut of bees simultaneously exposed also to Nosema spores, as evidenced by immunohistochemical data. Exposure to low dose of thiamethoxam (0.00856 ng bee ${ }^{-1}$ ) simultaneously with Nosema spores had a slight effect on the AHB. The same phenomenon was observed in the Carniolan bee, as evidenced by the survival of workers exposed to the lowest dose of thiamethoxam or Nosema spores longer time in comparison to AHB.

Taking together our experiment thus clearly demonstrated the cytotoxic effect of thiamethoxam on the midgut epithelium using cell death immunohistochemical detection method. Thiamethoxam slightly decreased spore production in AHB co-exposed to $N$. ceranae in a dose-dependent manner by the 5th day postinfection. Similarly, in Carniolan honey bees, infection development in the first 5 days was faster in bees inoculated only with Nosema spores and in bees inoculated with Nosema plus the low dose of thiamethoxam $\left(0.00856 \mathrm{ng}\right.$ bee $\left.^{-1}\right)$ than bees inoculated with Nosema and a high dose of thiamethoxam (0.0856 ng bee ${ }^{-1}$ ). Both AHB and Carniolan bees co-exposed to Nosema spores and thiamethoxam did not appear to be linked in enhancing $N$. ceranae virulence. Further investigations are necessary to clarify the mechanisms responsible for the bee responses to different thiamethoxam doses and $N$. ceranae infection. Physiological mechanisms involved in these interactions remain poorly understood and even appear to be contradictory (Vidau et al., 2011).

Our data provides novel insights into the toxic effects of different doses of the neonicotenoid thiamethoxam comparatively on the AHB and Carniolan honey bee life span, as well as the effects of simultaneous application of thiamethoxam and $N$. ceranae spores to honey bees. Induced bee mortality and increased cell death in the midgut mainly at the beginning of Nosema infection are the main effects at the individual bee level. The additive effects of both the Nosema infection and thiamethoxam exposure on epithelium degeneration would be the main factors leading to individual bee mortality by deprivation of nutrient absorption in the intestine. A better understanding of the physiological effects induced both by thiamethoxam and the Nosema infection will be essential to elucidate the effects observed on increased individual honey bee or colony mortality.

\section{Acknowledgments}

We are grateful for the assistance provided by Mitja Nakrst in the experiments and sample collections, and by Yvonne Bernik for English editing and to two anonymous reviewers for their important comments. We especially thank Dr. Fabio C. Abdalla for providing the laboratory (LABEF) for photodocumentation of the midgut histological sections of Africanized honey bee, as well as Caio Eduardo da Costa Domingues for the help with photo plates. This research was financially supported by the Slovenian Research Agency, Research Programme P4-133 and FP7 Project CropSustaIn, grant agreement FP7 - REGPOT - CT2012-316205, as well as financial support from Brazilian agencies CNPq (490379/2011-7) and FAPESP (2013/09419-4).

\section{References}

Alaux, C., Brunet, J.L., Dussaubat, C., Mondet, F., Tchamitchan, S., Cousin, M. Brillard, J., Baldy, A., Belzunces, L.P., Le Conte, Y., 2010. Interactions between Nosema microspores and a neonicotinoid weaken honeybees (Apis mellifera). Environ. Microbiol. 12, 774-782.

Aufauvre, J., Biron, D.G., Vidau, C., Fontbonne, R., Roudel, M., Diogon, M., Vigues, B., Belzunces, L.P., Delbac, F., Blot, N., 2012. Parasite-insecticide interactions: a case study of Nosema ceranae and fipronil synergy on honeybee. Sci. Rep. 2, 326.

Aufauvre, J., Misme-Aucouturier, B., Vigues, B., Texier, C., Delbac, F., Blot, N., 2014 Transcriptome analyses of the honeybee response to Nosema ceranae and insecticides. PLos One 9, e91686.

Bernet, D. Schmidt, H, Meier, W, Burkhardt-Holm, P., Wahli, T, 1999, Histopathology in fish: proposal for a protocol to assess aquatic pollution. J. Fish. Dis. $22,25-34$.

Botías, C., Martín-Hernández, R., Barrios, L. Meana, A., Higes, M., 2013. Nosema spp: Infection and its negative effects on honey bees (Apis mellifera iberiensis) at the colony level. Vet. Res. 44, 25.

Calderón, R.A., Van Veen, J.W., Sommeijer, M.J., Sanchez, L.A., 2010. Reproductive 
biology of Varroa destructor in Africanized honey bees (Apis mellifera). Exp. Appl. Acarol. 50, 281-297.

Cornman, R.S., Tarpy, D.R., Chen, Y., Jeffreys, L., Lopez, D., Pettis, J.S., Van Engelsdorp, D., Evans, J.D., 2012. Pathogen Webs in collapsing honey Bee colonies. PLos One 7, e43562.

Cox-Foster, D.L., Conlan, S., Holmes, E.C., Palacios, G., Evans, J.D., Moran, N.A., 2007. A metagenomic survey of microbes in honey bee colony collapse disorder. Science 318, 283-287.

Decourtye, A., Devillers, J., Genecque, E., Le Menach, K., Budzinski, H., Cluzeau, S., Pham-Delegue, M.H., 2005. Comparative sublethal toxicity of nine pesticides on olfactory learning performances of the honeybee Apis mellifera. Arch. Environ. Contam. Toxicol. 48, 242-250.

Del Aguila, C., Izquierdo, F., Granja, A.G., Hurtado, C., Fenoy, S., Fresno, M., Revilla, Y., 2006. Encephalitozoon microsporidia modulates p53-mediated apoptosis in infected cells. Int. J. Parasitol. 36, 869-876.

Dussaubat, C., Brunet, J.L., Higes, M., Colbourne, J.K., López, J., Choi, J.H., 2012. Gut pathology and responses to the microsporidium Nosema ceranae in the honey bee Apis mellifera. PLoS One 7, e37017.

Dussaubat, C., Maisonnasse, A., Alaux, C., Tchamitchan, S., Brunet, J.L., Plettener, E., 2010. Nosema spp. infectation alters pheromone production in honey bee (Apis mellifera). J. Chem. Ecol. 36, 522-525.

García-Palencia, P., Martín-Hernández, R., González-Porto, A.V., Marin, P., Meana, A., Higes, M., 2010. Natural infection by Nosema ceranae causes similar lesions as in experimentally infected caged-worker honey bees (Apis mellifera). J. Apic. Res. 49, 278-283.

Gavrieli, Y., Sherman, Y., Ben-Sasson, S.A., 1992. Identification of programmed cell death in situ via specific labeling of nuclear DNA fragmentation. J. Cell Biol. 119, 493-501.

Girolami, V., Mazzon, L., Squartini, A., Mori, N., Marzaro, M., Di Bernardo, A., Greatti, M., Giorio, C., Tapparo, A., 2009. Translocation of neonicotinoid insecticides from coated seeds to seedling guttation drops: a novel way of intoxication for bees. J. Econ. Entomol. 102, 1808-1815.

Godfray, H.C.J., Blacquièren, T., Field, L.M., Hails, R.S., Petrokofsky, G., Potts, S.G., Raine, N.E., Vanbergen, A.J., McLean, A.R., 2014. A restatement of the natural science evidence base concerning neonicotinoid insecticides and insect pollinators. Proc. R. Soc. B 281, 20140558.

Goulson, D., Nicholls, E., Botías, C., Rotheray, E.L., 2015. Bee declines driven by combined stress from parasites, pesticides, and lack of flowers. Science 347. http://dx.doi.org/10.1126/science.1255957.

Guzmán-Novoa, E., Vandame, R., Arechavaleta, M.E., 1999. Susceptibility of European and Africanized honey bees (Apis mellifera L.) to Varroa jacobsoni Oud. in Mexico. Apidologie 30, 173-182.

Gregorc, A., Bowen, I.D., 2000. Histochemical characterization of cell death in honeybee larvae midgut after treatment with Paenibacillus larvae, amitraz and oxytetracycline. Cell Biol. Int. 24, 319-324.

Higes, M., Garcia-Palencia, P., Martín-Hernández, R., Meana, A., 2007. Experimental infection of Apis mellifera honeybees with Nosema ceranae (Microsporidia). J. Invertebr. Pathol. 94, 211-217.

Higes, M., Martín-Hernández, R., Botías, C., Garrido-Bailón, E., González-Porto, A.V., Barrios, L., 2008. How natural infection by Nosema ceranae causes honeybee colony collapse. Environ. Microbiol. 10, 2659-2669.
Huang, W.F., Solter, L.F., 2013. Comparative development and tissue tropism of Nosema apis and Nosema ceranae. J. Invertebr. Pathol. 113, 35-41.

James, E.R., Green, D.R., 2002. Infection and the origins of apoptosis. Cell Death Differ. 9, 355-357.

Maienfisch, P., Angst, M., Brandl, F., Fischer, W., Hofer, D., Kayser, H., Kobel, W. Rindlisbacher, A., Senn, R., Steinemann, A., Widmer, H., 2001. Chemistry and biology of thiamethoxam: a second generation neonicotinoid. Pest Manag. Sci. 57, 906-913.

Martín-Hernández, R., Meana, A., Prieto, L., Salvador, A.M., Garrido-Bailon, E., 2007. Outcome of colonization of Apis mellifera by Nosema ceranae. Appl. Environ. Microbiol. 73, 6331-6338.

Matylevitch, N.P., Schuschereba, S.T., Mata, J.R., Gilligan, G.R., Lawlor, D.F. Goodwin, C.W., Bowman, P.D., 1998. Apoptosis and accidental cell death in cultured human keratinocytes after thermal injury. Am. J. Pathol. 153, 567-577.

Oliveira, R.A., Roat, T.C., Carvalho, S.M., Malaspina, O., 2014. Side-effects of thiamethoxam on the brain and midgut of the africanized honeybee (Hymenopptera: Apidae). Environ. Toxicol. 29, 1122-1133.

Pilling, E., Campbell, P., Coulson, M., Ruddle, N., Tornier, I., 2013. A four-year field program investigating long-term effects of repeated exposure of honey bee colonies to flowering crops treated with thiamethoxam. PLoS One 8. http:// dx.doi.org/10.1371/journal.pone.0077193.

Pettis, J.S., Van Engelsdorp, D., Johnson, J., Dively, G., 2012. Pesticide exposure in honey bees results in increased levels of the gut pathogen Nosema. Naturwissenschaften 99, 153-158.

Retschnig, G., Neumann, P., Williams, G.R., 2014. Thiacloprid-Nosema ceranae interactions in honey bees: host survivorship but not parasite reproduction is dependent on pesticide dose. J. Invertebr. Pathol. 118C, 18-19.

Sandrock, C., Tanadini, M., Tanadini, L.G., Fauser-Misslin, A., Potts, S.G., 2014. Impact of chronic neonicotinoid exposure on honeybee colony performance and queen supersedure. PLoS One 9, e103592.

Scanlon, M., Leitch, G.J., Shaw, A.P., Moura, H., Visvesvara, G.S., 1999. Susceptibility to apoptosis is reduced in the microsporidia infected host. J. Eukaryot. Microbiol. 46, 34S-35S.

Stoner, K.A., Eitzer, B.D., 2012. Movement of soil-applied imidacloprid and thiamethoxam into nectar and pollen of squash (Cucurbita pepo). PLoS One 7, e39114.

Teixeira, E.W., Santos, L.G., Sattler, A., Message, D., Alves, M.L.T.M.F., Martins, M.F Grassi-Sell, M.L., Francoy, T.M., 2013. Nosema ceranae has been present in Brazil for more than three decades infecting Africanized honey bees. J. Invertebr. Pathol. 114, 250-254.

Tan, J., Galligan, J.J., Hollingworth, R.M., 2007. Agonist actions of neonicotinoids on nicotinic acetylcholine receptors expressed by cockroach neurons. Neurotoxicol $28,829-842$.

Van Engelsdorp, D., Evans, J.D., Saegerman, C., Mullin, C., Haubruge, E., Nguyen, B.K. Frazier, M., Frazier, J., Cox-Foster, D., Chen, Y., Underwood, R., Tarpy, D.R. Pettis, J.S., 2009. Colony collapse disorder: a descriptive study. PLoS One 4, e6481.

Vidau, C., Diogon, M., Aufauvre, J., Fontbonne, R., Vigues, B., 2011. Exposure to sublethal doses of fipronil and thiacloprid highly increases mortality of honeybees previously infected by Nosema ceranae. PLoS One 6, e21550. 